\title{
Models and frameworks for a successful virtual learning environment (VLE) implementation
}

\author{
Ayman Ahmed AlQudah \\ Deanship of E-Learning and Distance Learning, University of Dammam, Ad Dammam, Saudi Arabia \\ Email address: \\ alqudah@hotmail.com
}

\section{To cite this article:}

Ayman Ahmed AlQudah. Models and Frameworks for a Successful Virtual Learning Environment (VLE) Implementation. American Journal of Software Engineering and Applications. Vol. 3, No. 4, 2014, pp. 33-45. doi: 10.11648/j.ajsea.20140304.11

\begin{abstract}
E-learning has become one of the major components in education processes, and it is one of the most important elements in which universities can attain a competitive advantage. Virtual learning environment (VLE), which is considered as a subpart of the LMS, allows educators and educational systems to go beyond place and ti.me in communication with every student. For this reason universities focus on having LMS, for it helps users access educational sources that is not only reliable, but also has the possibility to be integrated with other systems available at the university. The paper highlights and explores the different theories and methodologies related to implementing and switching virtual learning environment successfully. Many previous studies, framework, theories and models have been reviewed; those models and frameworks identify how successful the implementation of virtual learning environments is in higher educational institutes.
\end{abstract}

Keywords: E-Learing, Virtual Learning, Educational Sources Online

\section{Introduction}

Virtual learning environment (VLE) does not refer to or specifically mean educational site, nor a system including $3 \mathrm{D}$ or virtual reality classes and rooms. It is not also restricted to distance learning or to well-structured information spaces, its purpose is to enrich class room activities also use multiple pedagogical approaches, and different technologies should be integrated to create the VLE. It is not synonymous to a virtual campus; a virtual campus is the sub part of VLE (Beastall and Walker, 2007). Between these over general and over-specific definitions the VLE could be a mixture of these definitions, which are social space that contains text-based interfaces to the most complex 3D, and the integration of multiple tools which reproduce most functions thatcan be found on a real campus. These points illustrate the fact that implementing VLE is a big challenge, and this is the core aim of this paper: to implement and change management processes related to switching from one VLE to another or adapt a new VLE that will be assessed and critically evaluated in the next pages.

\section{Proposed Frameworks Provided by Alhogail and Mirza (2011), to Successfully Implement VLE on a Higher Educational Institution}

This model represents the summary while relying on approaches, research and ways that certain universities conduct to create and build a model that is appropriate for their needs and is cost effective. Some of these universities are York University, the University of Lincoln, H.P. University, and Oxford Books university as shown in table 1 below: 
Table 1. A comparison of the carrying out of each task of the frame work in four universities VLE implementation case, Alhogail and Mirza (2011)

\begin{tabular}{|c|c|c|c|c|}
\hline The Task & York University & $\begin{array}{l}\text { University of } \\
\text { Lincoln }\end{array}$ & $\begin{array}{l}\text { Oxford brooks } \\
\text { University }\end{array}$ & H.P. University \\
\hline Analysis of institutional context & & & $\checkmark$ & $\checkmark$ \\
\hline Sufficiency of resources & & & & $\checkmark$ \\
\hline $\begin{array}{l}\text { Selection of the VLE that support the language of academic staff } \\
\text { and student }\end{array}$ & \multicolumn{4}{|c|}{$\begin{array}{l}\text { None of these came across this task as in all the four universities cases, language } \\
\text { was not problem }\end{array}$} \\
\hline Getting people support and ownership & $\checkmark$ & $\checkmark$ & $\checkmark$ & $\checkmark$ \\
\hline Creation of the user coalition group that cover all stakeholders & $\checkmark$ & $\checkmark$ & $\checkmark$ & \\
\hline Design training programs to empower people to effect change & $\checkmark$ & $\checkmark$ & $\checkmark$ & $\checkmark$ \\
\hline Creation of the change agent to communication the change vision & $\checkmark$ & & $\checkmark$ & $\checkmark$ \\
\hline Increasing the awareness the of the selected VLE & $\checkmark$ & $\checkmark$ & $\checkmark$ & $\checkmark$ \\
\hline Setting of clear targets & & & $\checkmark$ & \\
\hline Establishing VLE help desk & $\checkmark$ & $\checkmark$ & & \\
\hline Gradual implementation of the VLE across the university & $\checkmark$ & & & \\
\hline
\end{tabular}

This model (Figure1) has been built in accordance with actual experience and practices, and is built by higher educational institutions that implemented VLE successfully. This model consists of eight distinguished, but interactive functions, and were applied correctly. As a result of proper implementation, their success is expected. The following paragraphs provide a brief summary about each stage of the models:



Figure 1. Frameworks to successful implement VLE in higher education institution that is based on change management approach

\subsection{Analysis of the Constitutional Context}

This primary stage is considered to be an important stage due to its analysis of environmental change, which is counted as a vital phase in any changing process (Sharpe et al, 2006). An analysis of weakness, strength and opportunity in the institution's objectives and plans are necessary in order to be compatible with the expected changes made by the institution. The institution determines for initiatiation, especially in VLE change.

This change is based on a proposed framework, initiated according to a bottom-up planning strategy, which means that each faculty dean is aware of it, and participates in the changing process. In addition, there are deans who are aware of changing benefits and are obliged to see it through.

\subsection{Sufficient Resources}

According to Beastall, and Walker (2007), prior change process intuition must be assured of having the necessary element that leads to the project or change required by the institution's determination to initiate; such elements include the solid infrastructure available in an institution, and skilled operators' training, technical support, and financial resources. Lacking one of them may lead to the failure of the VLE project.

\subsection{Selection of the VLE that support the language}

It is the process of selecting VlE that supports multiple languages. In addition, this must be taken into serious consideration when it is chosen for countries in which the English language is a second language. Thus, a language barrier should not affect the implementation of VLE and limits its effectiveness (Ardito et al, 2005).

When selecting VLE, there are some critical elements which must be taken into consideration in order to have a successful project. These elements include desirable functions such as video chat, white board, lecture capturer, and calendar. Some countries use the lunar calendar such as Saudi Arabia, while others use the solar calendar (Alhogail and Alhogail, 2011). Thus, the chosen VLE must overcome such elements which may hinder its success. 


\subsection{Getting the support of people and ownership}

It is natural to have resistance to change especially when it comes to replacing IS, or selecting a particular VLE (Cook, 2009). Therefore, such resistance must be taken seriously by VLE developers, and make their best effort to reduce such resistance in order to provide a smooth transition (Dublin, 2004). The model shown below suggests some steps that may be considered by developers to achieve this objective

Creating a user coalition group that covers all stakeholders: the main objective of this step according to the model is to gather as much possible information as we can from all personnel that may be affected, and be involved in the project especially in the system change and adoption, such as technical people, students, instructors, involved managers, registrars and others in order to reveal the expected problems. Hence, suggested solutions will be provided; furthermore, providing these information to a senior management with all ongoing developments will guide the process, and assure the senior management what these stakeholders want from the system, what benefits they may obtain, and how to deal with their concerns as well.

- Designing and developing training programs for empowering people involved in implementation will reduce resistance to change. The objective of the suggested empowering programs provide staff with necessary computer skills in order to handle the system properly such as: Workshops, seminars, training programs etc. Computer skills are not limited to creation of the content in the VLE, chat discussion groups, and others.

- Changing the agents' team in order to supervise the changing process: every successful project change should have a team whose sole purpose is to supervise the change process (Russell, 2009) by opening all communication channels with the people involved and with top managements. The process facilitates the change project while eliminating or reducing obstacles; thus, achieving the major goals that perceives the vision of the people and management involved with change.

- Increasing the awareness of the selected VLE: this step involves online engagement between students and instructors. The purpose of this step is to minimize resistance to change.

\subsection{Setting clear targets}

- The availability of benchmarks and quantitative measurements are vital to the success of any project in order to determine the success of VLE's implementation strategy (sharp et al 2006). For example, we have a clear target by determining the number of courses which must be implemented and uploaded to the institution's VLE system by the end of a specific date (by the end of June 15, we must have 50 courses implemented on VLE). While taking into consideration any difficult problems arising at this stage, the problem should be detected and solved.

\subsection{Establishing VLE help desk}

The aim of this step is to provide assistance for those who encounter problems with the new system. Gradual implementation of VLE across the institution aims at building new systems gradually while making use of the stakeholder's feedback in every step. By doing so, there will be a chance at solving arising problems and facilitating the implementation (Alhogail and Alhogail, 2011).

\subsection{Model Evaluation and Critical Review}

The above explained model aims at how to manage and support the change towards the implementation of VLE, which focuses on the importance of bottom-up change strategy. By doing so, resistance of change is reduced and allows the stakeholders at the bottom of the hierarchy to discuss the changes, aims, and challenges. Furthermore, this model provides a road map on how to implement VLE in the institution while taking into consideration change management and stakeholders who are involved in the process of change by granting them an opportunity to express their opinion and concerns.

Although, this model was reviewed properly, several previous studies were conducted on actual experiments done by universities that initiated change; however, it does not determine the project's implementation realistically. In order to have strong evidence that this model adds to the value of strategies implemented on higher educational institutions throughout the world, it is important to gather all types of stakeholders with different backgrounds that may not lead to a homogeneous response and understanding. Plus, having these stakeholders share their skills and experiences on how to implement VLE may constitute a challenge and difficulty (Ward et al, 2010).

\section{IEEE Draft Standard for Learning Technology, Learning Technology Systems Architecture LTSA}

IEEE, Institute of Electrical and Electronics Engineers, is considered to be one of the most important and largest establishments that set forward influential standardizational bodies at word level (Derntl and Motschnig-Pitrik, 2004), Electronic Education Technology is one of the applications that IEEE has put forward, which is called the draft standard or the learning technology system architecture (LTSA) according to this standard model. This is shown in the figure below (2): 


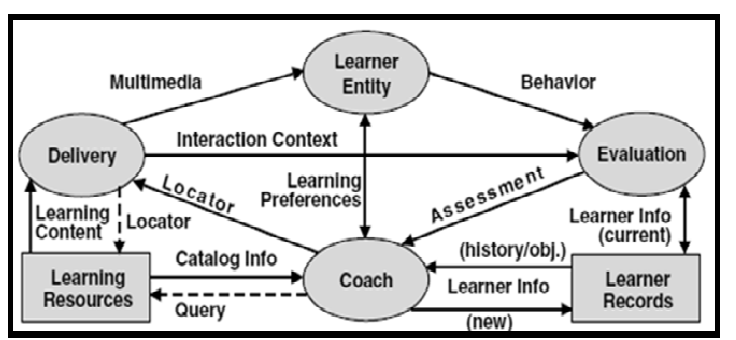

Figure 2. Learning Technology Systems Architecture (LTSA) system components. (IEEE, 2001)

This model aims at facilitating and dividing e-learning systems and its subsystems, and the ways they interact with each other. This model shows a very broad approach in creating strategy to develop and build VLE (Derntl and Motschnig-Pitrik, 2004). The model primarily focuses on the technical view point. This means if any company or individual is willing to create this system, they must make use of this model as an essential reference to deal with in the way systems interact with each other.

This system consists of three components:

a- Process: Learning, coaching, evaluating, and delivering.

b- $\quad$ Stores : Learner records and learning resources

c- Flows: multimedia, behavior, assessment, interaction context, locator, learning content, catalogue information, etc.

These components are explained as follows:

Learning entity: it may be a single learner, multiple learners, or a human element that process and deal with the rest of the components through multimedia. Multimedia is received in a learner's entity (Pdf, Word, etc). The learner's entity reacts with multimedia through observation and evaluation, as his or her behavior will be subjected to evaluating the entity. In other words, when actually building a system, a learner's entity needs a computer screen to submit multimedia to the learner, or by any other means that would help the learner's entity to understand and comprehend the content.

- Evaluation entity: theoretically, evaluation entity provides measurements of learning. To process or assess for instance, a coach expert uses a certain test, such as a multiple choice test, thus the functions of the evaluation entity are determined as the correct responses through an interaction context and link with a learner's current information send the results to the coach in assessment form.

- Coach entity: represents the learner's retrieval of information from various sources such as learner's information, learner's preferences, and learning content the learner receives through multimedia

- Learning resources: it's the place where the learner's educational level of students is stored, like experience, education or learning instruments such as assignments, tutorials, videos, pdf, etc. In addition, learning resources constitute primarily a place for retrieving learning material content. To shed more light on this subject, below is an illustrative example: query an order for mathematics. The query returns a set of information relevant to mathematics, which is distributed according to certain aspects that involves mathematics as video or pdf of mathematics.

- Delivery: Represents the concept of information delivery which is obtained from learning resources to learner entity through multimedia or information learning resources in order to evaluate interactive contexts.

- Learner record: it is the place to store learner's information, such as past learning experience. The results of current assignments are recorded with the students' current performance.

\subsection{Model Evaluation and Critically Review}

This model provides excellent approaches and practical ones in order to understand the interaction process of the learning management system (LMS). Furthermore, a full description of the function is provided by each element for the purpose of having successful LMS software. The model primary focuses on how the system's elements interact with each other, regardless of the rest of the elements that virtual learning environment (VLE) implementation requires in pedagogical elements (Derntl and Motschnig-Pitrik, 2004).

This model is based on technical points of view while ignoring the aspects of other important elements such as social-technical and psychological aspects in VLE implementation. However, IEEE LAST standards can be used in evaluation learning management system to see whether this system is compatible with LAST standerds due to its being a pure technical point of view.

\section{Saeedikiya et al. (2010) Model}

According to this model, Saeedikiya suggests six stages to implement e-learning in traditional universities. Any process of establishing an e-learning system at any university should go through six major steps as shown below:

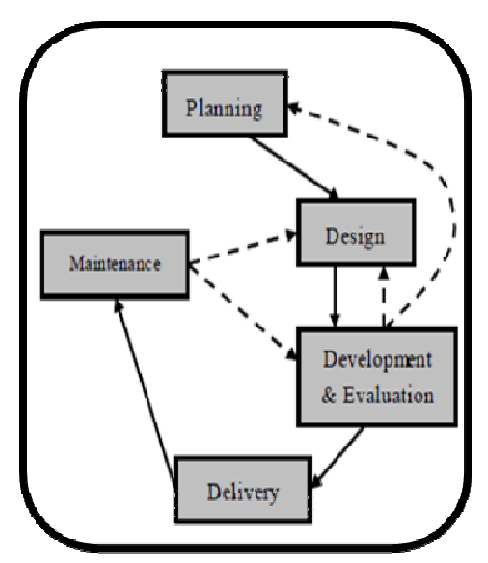

Figure 3. Sequences of stages of e-learning implementation according to Saeedikiya et al. (2010) 
The Following is a Summary of the Model Steps:

1. Diagnoses: it consists of the evaluation of the current institutional status of the of E-learning system, followed by an establishment of a financial, educational and strategic plan for change. This step requires the participation and cooperation of institutional mangers, business managers, and E-learning experts.

2. Decision-making: it consists of the LMS's decision making to fulfill the university's needs. This suggests that LMS must determine and clarify the students' needs and their expectations from the system (Ardito et al, 2005). In addition, it is used to determine the financial and technical resources of the university.

3. Design: this step calls for the participation of E-learning experts, technical experts, subject matter experts, and institutional designers. The design step aims at content design learning to use the E-learning system effectively (Ssekakubo et al, 2011).

4. Development: establishing a pilot project of the system is created in order to observe the system's functions, and to resolve problems that may emerge during implementation, in addition to conducting a system evaluation after its testing. This step aims at helping students and instructors in their dealings with the system, and to ensure the accuracy of the way in which they deal with the system.

5. Post-delivery: follows up the E-learning system development through student and instructor's training, and providing them with technical support in order to have their feedback.

By understanding in steps, it is clear that the model focuses on the following items primarily when establishing E-learning systems:

- The building of an E-content must be conducted by experts, and not through arbitrary ways that depend on instructors alone. Thus, experts should participate in content building process.

- Personal training and guidance on best utility of the system.

- Have information technological staff in transformation and implementation of E-learning system, because consequently they will be the ones in charge of managing the systems at their universities.

This model is similar to another model developed by Khan, (2004). Khan's model is divided into six steps with three sequences:

- Content development consists of planning, design and development of an E-learning system.

- Content delivery consists of evaluation and delivery of the E-learning system.

- Content maintenance deals with maintenance of an E-learning system.

This model introduces a simple way in understanding the process of the E-learning system at a university level, and the role of various personnel in the building process of an E-learning, while taking into consideration the educators' role in the success of the E-learning system.

Table 2. Stages of e-learning implementation, According to saeedikiya et al. (2010) and Khan

\begin{tabular}{|c|c|c|c|c|c|c|}
\hline $\begin{array}{l}\text { According to } \\
\text { Saeedikiya et al (2010) }\end{array}$ & Diagnosis & $\begin{array}{l}\text { Decision } \\
\text { Making }\end{array}$ & Design & Development & Delivery & Post Delivery \\
\hline $\begin{array}{l}\text { According to Khan } \\
\text { (2004) }\end{array}$ & planning & & Design & $\begin{array}{l}\text { development and } \\
\text { evaluation }\end{array}$ & Delivery & Maintenance \\
\hline
\end{tabular}

\subsection{Model Evaluation and Critical Review}

Although this model is simple and easy to use, especially in strategic planning for VLE implementation, the model needs various experts with different backgrounds such as E-learning experts, technical experts, subject matter experts, software evaluation experts, and business management experts. In addition, all of these needed experts will raise the costs, and cause contradictory points when implementing VLE.

\section{Khan's Frameworks}

This model provides an idea on how planning is set forward, along with E-learning development, management and assessment.

Blended learning is integrated in E-learning with traditional learning (face to face) in one framework. E-learning instruments are employed in teaching without abandoning actual and accustomed learning, which is physically attending the class room (Hameed et al 2009).

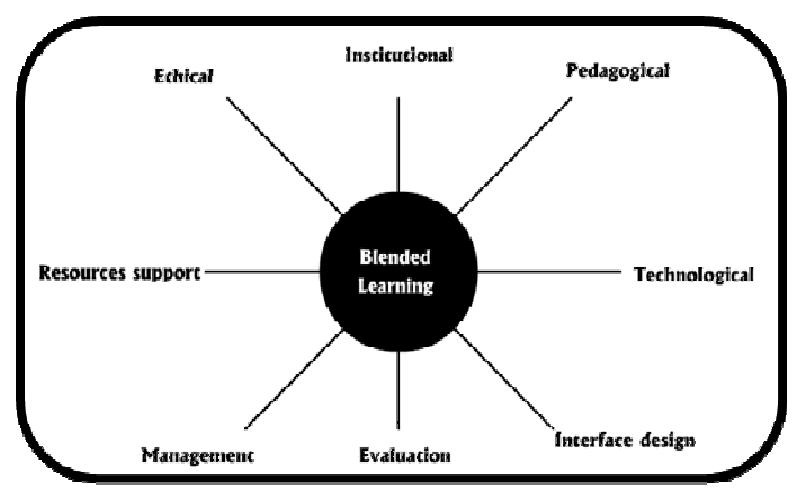

Figure 4. Khan's framework (Singh, 2003)

Khan's framework consists of the following major steps:

Institutional, pedagogical, technological, recourses support, ethical, interface, design, evaluation and management. Each one of the above mentioned steps 
represent a set of sub steps and issues that must be dealt with in order to make blended learning successful (Khan, 2006).

\subsection{Institutional: Consists of Three Dimensions}

This sub step dimension focuses on examining the users' expectation from the system users such as (academic staff, students, and administrative staff) to know what users expect and reveal their demands, which are considered to be essential steps towards system development.

The second dimension focuses on academic aspects of system building and change process, in terms of the availability of electronic and scientific contents to be delivered through a system project used for developing the organization level.

The last dimension focuses on the administrative (managerial) affairs in the organization, which relates to the readiness of the organization's infrastructure. Thu author sees the significance of the availability of a strategic plan for the organization, and the extent of human resources and budget readiness in the organization can offer.

\subsection{Pedagogical}

It reveals the significance of the educational parameter that is extended in the building and transforming of the blended learning. This step aims at insuring the educational content which intends to provide objectivity in learning. To illustrate further, a student is requested to conduct an experiment in the chemical substance reaction, there must be an ability to program E-learning that allows students to conduct this experiment through some tools as E-simulation.

\subsection{Technological}

This step ensures that the organization possesses hardware and software along with technological skills are necessary for building the system and dealing with software; hardware such as servers and networks, software such as LMS (learning management system) and LCMS (learning content management system).

\subsection{Interface Design}

Blended learning is utilized in many universities (Hameed et al 2009). The student's lecture is online, and he attends a traditional classroom for the other. At this phase, concentration is on the general appearance which allows access to learn materials with an attractive appearance.

\subsection{Evaluation}

Evaluation is a standard measurement that determines errors. It is the location and extent that one reaches in a system's application. Thus evaluation is important in order to know the usability extent of the system (Nokelainen, 2006). Without conducting evaluation, the university will not be able to know whether it has reached the intended level in the E-learning system. In addition, assessments determine the barriers that obstruct the benefits of the system and determines the defective place (Rovai et al, 2008 ).

\subsection{Management}

This step ensures that all of the steps in the system application are functioning in accordance with the project plan, and their projected timing and all that are involved in the change process are functioning integratively in order for the intended change and implementation of an E-learning system to reach a safer level.

\subsection{Resources Support}

This phase is intended to provide assurance to different resources available for the change process. Resources for students and instructors include online and offline material content. In addition, this phase is created for the students' convenience in learning, so they would feel comfortable in asking for help when they need their E-learning process.

\subsection{Ethical}

This model insists that in the process of designing and implementing the system's cultural diversity, the students' mode of learning and requirements are involved. Furthermore, this phase aims at providing system users with a good attitude, respect for privacy, and intellectual property rights (Khan, 2004).

\subsection{Model Evaluation and Critical Review}

Khan's framework provides a comprehensive vision on how to build and develop blended learning systems computable with learning objectives of the institutions, which are framed within a variable of "learning quality." How to achieve a flexible learning environment for a learner wherever they are? The answer to this question is the key for understanding Khan's framework. This model goes deeper into subjects and aspects with big details, for instance, the model consists of eight steps explained with extensive details, and each step has several issues. These issues have more branches and details needed to deal with. The model brings forward a new theme that is ethical in VLE implementations and adoption, when no other model or framework touches upon ethical issues.

Khan's model discusses change from different aspects as mentioned earlier; it is an extensive model that deals with the VLE's development and implementation from many angles, such as management, student-instructor interaction, and technicality. This model can be used in the strategic planning for implementing VLE.

\section{Systematic Change Management Strategies for an E-learning System Ghavifekr and Hussin (2011)}

Ghavifekr and Hussin (2011) provide the overview of the main, sub-themes and sub-sub themes of the systematic change management strategies for an E-learning system. 
This study provides in depth analysis of management functions, including planning, organizing, guiding, and monitoring the E-learning system as shown in table 3.

This model is based on Malaysian experiences that focused on transforming into an open distance learning system. The notion of the model reflects primarily on the major elements for building an E-learning system, and they are: planning, organizing, guiding, and monitoring.

Table 3. Main, sub, and sub-theme of systematic change management strategies for an e-learning system

\begin{tabular}{|c|c|c|}
\hline $\begin{array}{l}\text { Main } \\
\text { Theme }\end{array}$ & Sub-Themes & Sub-sub Themes \\
\hline \multirow{11}{*}{$\begin{array}{l}\text { Elearning } \\
\text { system }\end{array}$} & \multirow{4}{*}{ planning } & $\begin{array}{l}\text { - } \quad \text { Elearning system continuous } \\
\text { upgrading }\end{array}$ \\
\hline & & - E-support effectiveness \\
\hline & & - $\quad$ E-tools-services ,E-facilities \\
\hline & & E-budgeting \\
\hline & \multirow{3}{*}{ organizing } & $\begin{array}{l}\text { - E-leadership and e-environment } \\
\text { maintenance }\end{array}$ \\
\hline & & $\begin{array}{l}\text { - } \quad \text {-training programs and profession } \\
\text { development strategies }\end{array}$ \\
\hline & & $\begin{array}{l}\text { - E-content and E-learning } \\
\text { materials }\end{array}$ \\
\hline & \multirow{2}{*}{ Guiding } & $\begin{array}{l}\text { - Advanced objectives for } \\
\text { technology management }\end{array}$ \\
\hline & & $\begin{array}{l}\text { - Effective E-learning platform in } \\
\text { ODL Organization }\end{array}$ \\
\hline & \multirow{2}{*}{ Monitoring } & $\begin{array}{l}\text { Monitoring the utilization and } \\
\text { evaluate the effectiveness }\end{array}$ \\
\hline & & $\begin{array}{l}\text { - Continues monitoring of the } \\
\text { systems security and maintenance }\end{array}$ \\
\hline
\end{tabular}

This phase depends heavily on the availability of clear vision and strategic planning of E-learning systems.

The significance of clear vision relies on the answer of this question: "What to change?" While the strategic planning lies in the answer of "how to change? "(Bateman and Snell, 2007).

The Planning is conducted on four elements:

E-learning System Continuous upgrading

- $\quad$ E-support effectiveness

- $\quad$ E-tools, E-services, and E-facilities

- $\quad$ E-sources for the entire system

- Continuous Monitoring of System's Security and Maintenance

- $\quad$ E-budgeting management

\subsection{Organizing E-learning System in Two Elements}

a- The organization of structure.

b- The organization of arrangement.

These aim to transform the organization in a way that makes it ready and acceptable to change. The infrastructure of the organization in particular relies on skilled workers, financial sources, and E-content.

Organization is achieved through the availability of these elements:

- E-leadership and E-environment maintenance

- E-training programs \& professional development strategies
E-content and E-learning materials

\subsection{Guiding}

Consists of two major steps:

Advanced Objectives for Technology Management

- Effective E-learning Platform in ODL Organization

Guiding in general, E ensures that the two steps of advanced objectives and effectives of E-learning are complementing each other, aiming to achieve common goals with the presence of conflict between the two steps. Common goals are reflected in cost effectiveness and flexibility (Poole and Van de Ven, 2004).

\subsection{Monitoring}

The aim of monitoring is ensuring that the objective suggested in this model can be achieved, and knowing the actual performance of various departments involved in the change process will aid the progress. This can be achieved by the following two steps:

- Monitoring the utilization and evaluating effectiveness.

- Continuous monitoring of system's security and maintenance

\subsection{Model Evaluation and Critical Review}

The model focuses on quality of leadership and skilled management to direct the change and provide policies and strategies to help upper management ensure a successful change process. Also to focus primarily on strategic planning of E-learning without dealing sufficiently with technological matters of the issues. The focus on management of change gives the guidance and instructions the steps and policies taken into consideration, along with elements during change process sent to top and middle management.

\section{Kotter's Change Model}

It is possible to summarize this model by stating that the successful change in an organization is its need for sound planning, set by a solid foundation for change process in order to facilitate implementation and elevate the level of a higher success, whereas the success of organizations lie in the eight steps of the following model; thus, an organization will be able to enjoy a real change as expected:

Kotter's change model consists of eight steps, each leads to a successful change process. The first four steps focus on defreezing the organization, while the next three steps focus on change implantation, and the last step involves refreezing of a new culture in the organization.

The summary of Kotter's model is as follows:

1. Establish a sense of urgency, an occuring change, the majority of involved people will show a good favor towards it (Rovai et al, 2008). In order to have a sense of urgency, subordinates must talk and show a willingness for change. 
2. Forming a powerful guiding coalition team would convince subordinates to make the change required for strong leadership with the support from upper management in an organization; whereas, it is not sufficient to mange change without leading it (Kotter, 1998). The leadership is in need for a group of influential people who promote change, by doing so, change will occur smoothly.

3. Create a clear vision expressed in simple forms; concepts and nations of change must be connected with the overall vision of the organization (Menchaca et al, 2003). The vision idea can be understood and accepted by people easily, because the clear vision facilitates the understanding of work expected from people involved.

4. Communicating the vision: primary purpose of this step is that whatever is done for this vision determines the success or failure of the organization's continuous communication of this vision throughout its organization, as it includes details in what the organization does. Thus, all employees will comprehend it entirely.

5. Empowering others to act in the vision: according to the author, following the previous steps allows one to reach an actual change. When talking about vision and establishing people's commitment at all levels of the organization with the support of top management permits the start of change.

In this step according to the author's organization, one must determine obstacles and eliminate them by doing the flowing:

- Determine the change in leaders and functions which leads to a safe change.

- Review the organization structure in order to guarantee it's appropriateness with the vision.

- Know and reward those who helped the change to occur.

- Determine those who resist changes and help them see the impotence of this change.

6. Plan for creating a short team that aims to win and succeed, this is the greatest motivator and drive (Poole et al, 2004). As a result, having short term goals will lead to long term goals. The success in short term objectives work as an additional motivational factor for all those who are involved in the change process.

7. Consolidations gain and make more changes: The early announcement for the success of change causes change failure (Kotter, 1998), where the real change must be managed deeply because swift wins are just the beginning for what must be gained in order to achieve a long term change.

8. Institutionalize the new approaches: in order to anchor the new culture caused by change in organization, change must be an essential part of organizational activates, along with the continuation of supporting change by change leaders.

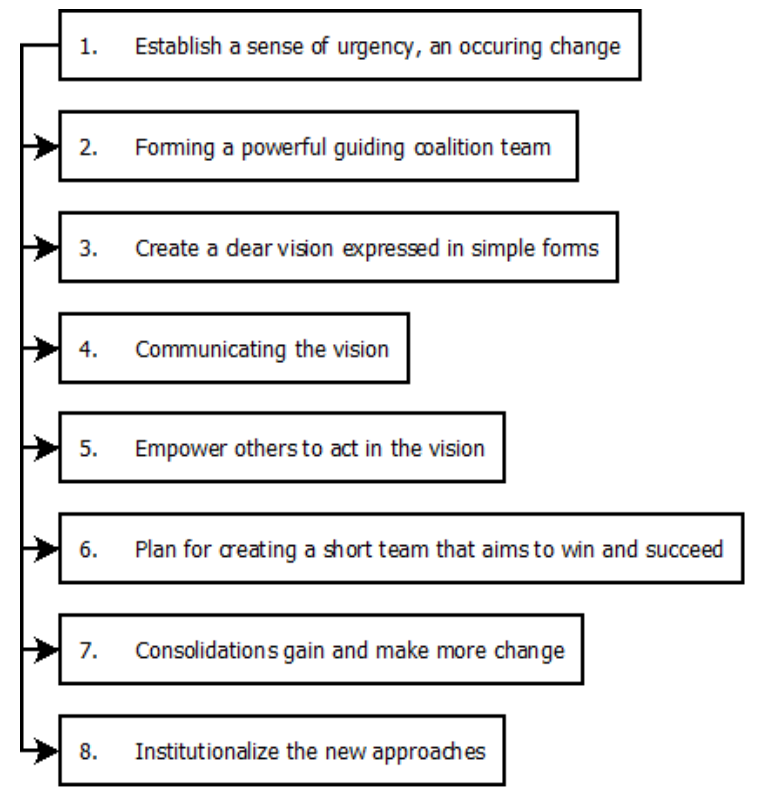

Figure 5. Kotter's change model (1998)

\subsection{Model Evaluation and Critical Review}

Although the model primarily focuses on change theories in terms of management, however, it is proper when implementing change from a management point of view. In addition, the model focuses on management and preparing individuals for implementing change. The model does not discuss technology's effects on the changes of the organization. The model provides strategic approaches for change to occur and change management. Thus, it has been utilized widely throughout the world. Talks about change from a sole and pure management perspective is what Kotter provides, he generally guides the steps required to initiate an effective change.

\section{CSU Change Model}

Carlo Sturt University is the first Australian university to establish an open electronic learning system on January 2008 (Uys et al, 2007). This model reflects a three years practical experience of change and innovation by the university during its development of E-learning systems from $2007-2009$.

This model is based on Kotter's model as explained earlier, yet Kotter's model focuses on change management. The CSU model consists of eight major steps which does not need a specific order for implementation (Uys, 2010). Whereas, it is possible to start with any step without abiding to order, however, it is possible to implement these steps simultaneously.

Prior to explaining this model, it is worth mentioning that this model is characterized by two major strategic factors in establishing E-learning:

a- Building E-learning communities.

b- Sharing best practices in E-learning system's implementation. 
It is worth mentioning that this model is characterized by a flowing bottom - up strategy. The above two sub steps indicate that the aim of this learning committee is to provide various topics relevant to a university's E-learning system
(CSU interact), discussing them among this committee members such as E-Learning system evaluation, visualizing online content, and attaining an E-portfolio.

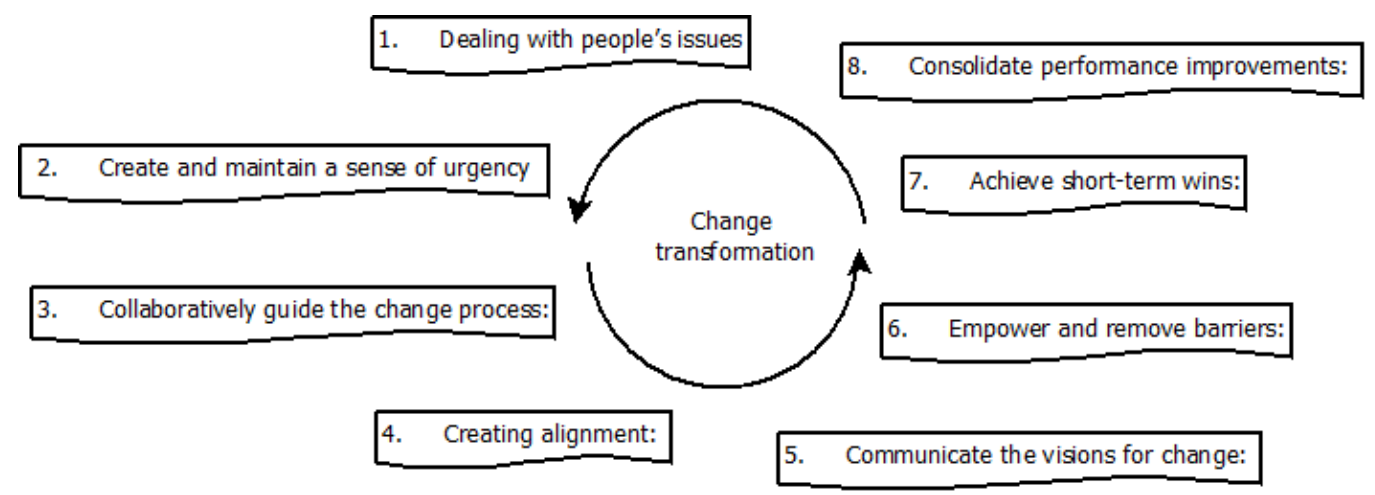

Figure 6. CSU Change model (Uys, 2010)

In regard to sharing best practices, these should be shared with others; it involves various topics relevant to E-learning systems such as course content design. Best practices are considered to be as reference to others because they express the summary of experience towards a certain topic.

Model Steps Summary:

1. Dealing with people's issues:

It is a stage whereas the model deals with academic staff. Marshall (2004) points out that having academic staff participate or be involved with change process leads to success of change. This stage aims at examining the extent of academic staff readiness to accept the change, and change the way they teach with it; in order to being part of the change or the ownership of the academic staff, their involvement is vital.

2. Create and maintain a sense of urgency:

This stage clarifies to employees throughout the university that the process of change and the university is in

need for such change, and this change may affect the performance of the university. The creator of this feeling is at top management (Poole et al, 2004). For instance deterring a due date which must be enabled by all academic staff has a site on the E-leaning system that carries out the course or leaning materials.

3. Collaboratively guide the change process:

Through the activity of the guiding team in various university departments, the change process is coordinated, and this reveal its importance of the aim of this step, which is to gather as many possible of motivated people for the change process.

4. Creating alignment:

To ensure the success of change process, this change must be harmonized with the university's plan, objectives and vision along with various faculties plan and objectify (Uys et al, 2007).

5. Communicate the visions for change:

Have staff and students be aware always regarding to the change and its objectives. The Carlo Sturt University implemented this step through communicating plans, which consists of four elements:

- E-mailing the occurrences of the university's E-learning system that is called CSU interaction.

- Establish communities along with stakeholders to elaborate and communicate the e-learning system.

- University adopts screen savers that display the change and whereabouts at the university.

- University utilizes blogging tools named Yammer which is an open source tool for change promotion. According to Uys (2010), all the above mentioned tools have maintained the spirit of change for three years, and promoted those who were involved and were aware of change's significance.

6. Empower and remove barriers:

Through training sessions and workshops, computer skills have been archived, while the E-learning system is considered to be needed for many involved users, especially faculty members. This stage aims to determining that obstacles add berries to hinder the application of the system, and this must be removed, especially those elements that accept ways for success.

7. Achieve short-term wins:

It has been noticed that the university has achieved short short-term wins during application stages throughout the running of the pilot project, which achieved tangible and clear results in regard to functions. The system is able to perform in the future at a university level.

8. Consolidate performance improvements:

The significance of this stage lies in the assurance that the system is constantly up to date and it's able to perform tasks with competence through establishing a plan to enhance the system continuously and have it subjected to improvements.

\subsection{Model Evaluation and Critical Review}

The model provides a framework which helps underhand the implementation of change in VLE at the university level. Starting from a strategic vision of change, the university ends up with changes that must be occurred at an 
individual's level in order to achieve favorable results in VLE application. One of the model's disadvantages lies in the difficulty in establishing team or committees from various interest and different back grounds.

\section{Successful System Implementation Factors by Zwass (1998)}

According to Zwass (1998), there are three key agents in implementing the information system (IS): End user, management, and the information system developer (figure 7). Each agent has a range of issues associated with it that must be achieved and satisfied in order to accomplish successful implantations of IS. For example: One of the most important issues concerning the end user that the system provides is the desire function they want.

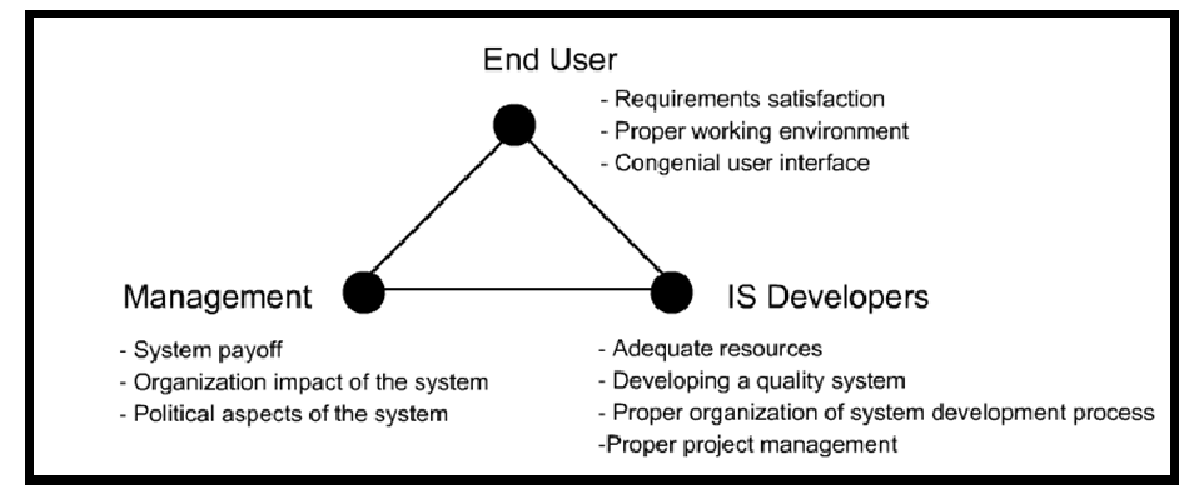

Figure 7. Key agent in information system development

According to Zwass (1998), the factors play a role in successful system implementations that are summarized as seen in figure 8 . These steps or seven elements should be used by managements in order to be sure that the implementation of its system is successful, due to the fact that the seven elements represent the successful system of a company that already has the characteristics of being successful. These factors are as follows:

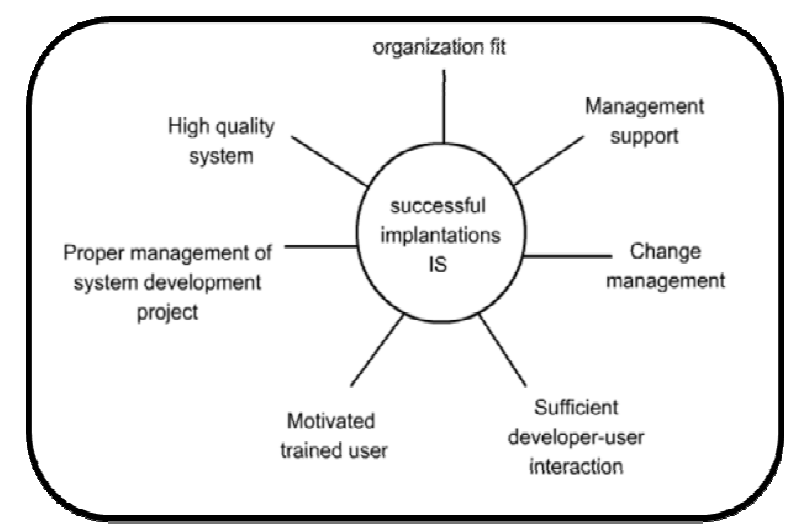

Figure 8. Factors in successful system (Zwass, 1998)

\section{1- Organization fit:}

This means to be sure that organization's objectives of the new Information system (IS), along with employees and workers who are affected by the organization orientation towards changes.

\section{2- Management support:}

Management support of IS is achieved by providing human resources, financial resources, hardware, and software due to being the essential elements for a module's successful implementation.

3- Change management:

During change occurrences, an organization goes through three stages or sequences: Unfreeze Moving, and Refreezing.

A- Unfreeze consists of motivational workers throughout the organization in regard to change, the importance of change and its benefits, along with training employees who are affected by the changes, and who will be in charge of change.

B- Moving is a phase in which the organization moves towards implementing the new system (installing the new system).

C- Refreezing is the adoption of the new system. The new system has become part of an organization. This phase should have a plenty of interaction between management and employees that are extensively used for the purpose of strengthening the system by getting people used to it, and to reduce some employee's resistance to the system (Kotter,1998); Thus, reducing employee resistance is a problem which changes management that should work and reduce it through several means such as training and participating in system implementation.

4- Sufficient interaction between developers and users:

The aim of this stage is to increase user's satisfaction with the system, thus users become independent in solving problems. In order to archieve this goal, a prototype approach should be tried to provide similar functions as the system's functioned by Zwass (1998). It is not costly and it is a fast built prototype, whereas the philosophy of prototyping is based on trying and refining, prototype is used when user's requirement is hard to determine (Richards et al, 2004), whereas it helps in solving this problem by having users participate in determining the system requirement and development.

5- Motivate and train users: 
Motivation is a significant factor in the quality and functionality of the system Zwass (1998). Thus, motivating people through training them via workshops and training programs and other means of motivation is a fruitful factor.

6- Proper management of a system development project:

The adaption of the new IS is a significant project which affects many parts of the quantization and carries potential risk (Buchan, 2010), thus, it is devisable to divide the project and implement on step bases.

7- System Quality:

The system must be convenient without causing complications to its users, within a reasonable cost, thus, if a system does not help in solving users' problems or lessen their complicated functions, this system is not accessible. The quality of any system relies upon the degree of use and user satisfaction.

\section{Model Evaluation and Critically Review}

The model can be used in strategic planning of VLE implementation and adoption. If VLE is considered to be an IS, the model ignores several important aspects of VLE adoption such as pedagogical elements in E-learning, this model discusses how strategic implementations of IS in an organization does not specify for VLE adoption.

\section{Summary}

Khan's model takes into account many issues to ensure that VLM implementation and education used by LMS shall be effective and will lead to a meaningful blending, learning experience. It is an extensive model that deals with VLE development and implementation from many angles such as management, student- instructor interaction, and technicality. The model brings forward a new theme that is ethical in VLE implementations and adoption, when no other model or framework discussed in literature touches the ethical issues. The proposed model by Ghavifekr and Hussin (2011) focused on identifying how implantation and adoption of VLE is used to open distance learning (ODL). The framework proposed by Alhogail and Mirza (2011) provides comprehensive vision of how to implement and adopt VEL. But it does not determine the implementation of the project realistically or actually in order to have strong evidence from the model. The given evidence adds value to strategies implemented on higher educational institutions. The framework is not implemented on the real world to find out the suitability of the theoretical framework with a practical framework.

Although Saeedikiya et al. (2010) model is simple and easy to use, especially in strategic planning for VLE implementation. However the model insists that in order to successfully implement and adopt VLE, there must be a large number of experts involved in the process of change. Various experts with different backgrounds such E-learning experts, technical experts, subject matter experts, software evaluation experts, and business management experts are relevant. In addition, all these needed experts would raise the costs and cause contradictory points of view in implementing VLE.

Zwass (1998) provides a framework that illustrates the factors that play a role in a successful information system IS implementation. The model ignores several important aspects of VLE adoption such as pedagogical elements in E-learning. This model discuses how to make strategic implement IS in organizations, while it does not specify for VLE adoption. The model can be used in strategic planning of VLE implementation and adopt if VLE is considered to be an IS.

IEEE Draft Standard for Learning Technology and the Learning Technology Systems Architecture LTSA aim at facilitating and dividing LMS systems and its subsystems, and the ways they interact with each other, regardless of the rest of the elements that virtual learning environment (VLE) implementation requires such pedagogical elements (Derntl and Motschnig-Pitrik, 2004). This model shows a very broad approach as to create strategy to develop and build VLE.

The CSU Model is based on Kotter's change model and reflects the Carlo Sturt University three years of practical experience of change and innovation by the university during the development of its VLE system. This study focused mainly on human issues that affect LMS using from students and staff perspective. The use of LMS is one of the core elements that affect VLE success. Khan's model consists of eight main stages to assure that the institution have a successful virtual learning environment, which provide blended learning. The stages are: Institutional, pedagogical, technological, recourses support, ethical, interface design, evaluation and management, which have been described previously in literature.

\section{Conclusion}

The paper highlights eight theoretical frameworks and explores the relationship between implementation and management change process, which is related to switching from one VLE to another or adapting a new VLE. All of these frameworks have been assessed and critically evaluated. Khan's frameworks can be used to manage the change process in universities that follow a blended learning way of education, Ghavifekr and Hussin (2011) propose that frmaworks can be used in case the university uses open distance learning (ODL) Saeedikiya's et al. (2010) model considers that there must be a large number of experts involved in the changing process which raises the costs of implementing VLE. Zwass (1998) and IEEE Draft Standard frameworks ignore important aspects of VLE adoption such as pedagogical elements in E-learning. As for the CSU Model, it focuses mainly on human issues that affect LMS used from students' and staff perspectives. Hence, this paper is important to highlight the needed frameworks and elaborates their importance to simplify online learning process in academia 


\section{References}

[1] Alhogail, A.A. and Mirza, A.A. (2011). IMPLEMENTING A VIRTUAL LEARNING ENVIRONMENT (VLE) IN A HIGHER EDUCATION INSTITUTION: A CHANGE MANAGEMENT APPROACH. Journal of Theoretical and Applied Information Technology.approach to planning, design, instruction, evaluation, and accreditation. New York, NY: Teachers College Press.approach to planning, design, instruction, evaluation, and accreditation. New York, NY: Teachers

[2] Ardito, C., Costabile, M.F., De Marsico, M., Lanzilotti, R., Levialdi, S., Roselli, T., and Rossano, V. 2005. An approach to usability evaluation of e-learning applications. Univ. Access Inf. Soc. 2006, 4: 270-283 Published online: 8 December 2005.

[3] Bateman, T. S., \& Snell, S. (2007). Management: Leading and collaborating in a competitive world (7th ed., pp. 16 -18). New York, NY:McGraw- Hill.

[4] Beastall, L. and Walker, R., "Effecting institutional change through e-learning: An implementation model for VLE deployment at the University of York", Journal of Organisational Transformational and Social Change, 3(3), (2007), 285-299.

[5] Bremer, D, Bryant, R. (2005) "A Comparison of two learning management Systems: Moodle vs Blackboard", Proceedings of the 18th Annual Conference of the National Advisory Committee on Computing Qualifications. pg135-1390CE

[6] Buchan, J. (2010). Putting ourselves in the big picture: A sustainable approach to project management for e-learning. The Journal of Distance Education, 24(1), 55-76.

[7] Bremer, D, Bryant, R. (2005) “A Comparison of two learning management Systems: Moodle vs Blackboard", Proceedings of the 18th Annual Conference of the National Advisory Committee on Computing Qualifications. pg135-1390CE

[8] Cook, D. A. 2009. The failure of e-learning research to inform educational practice, and what we can do about it. Informa, 2009, 31(2):158-162

[9] Derntl, M. \& Motschnig-pitrik, R. (2004). Patterns for Blended, Person-Centered Learning: Strategy, Concepts, Experiences, and Evaluation. ACM Symposium on Applied Computing. - (-), 916-923.

[10] Dublin, L., (2004), "The nine myths of elearning implementation: ensuring the real return on your e-learning investment",Industrial and Commercial Training, 36(7),(2004), 291-294.

[11] Ghavifekr, S. \& Hussin, S. (2011). Managing Systemic Change in a Technology-based Education System: A Malaysian Case Study. Procedia - Social and Behavioral Sciences. 28 (-), 455-464.

[12] Hameed, S., Fathulla, K., and Thomas, A. 2009. Extent of e-learning effectiveness and efficiency in an integrated blended learning environment. Newport CELT Journal, 2:52-62.

[13] Hameed, S., Fathulla, K., and Thomas, A. 2009. Extent of e-learning effectiveness and efficiency in an integrated blended learning environment. Newport CELT Journal,

\section{2:52-62.}

[14] IEEE. Draft Standard for Learning Technology - Learning Technology Systems Architecture (LTSA) (IEEE P1484.1/D9), 2001.

[15] Johnson, S., Aragon, S., Shaik, N. and Palma-Rivas, N. (2000). Comparative Analysis of Learner Satisfaction and Learner Outcomes in Online and Face-to-Face learning Environments. Journal of Interactive Learning Research. Vol 11(1). pp $29-49$.

[16] Johnson, S., Aragon, S., Shaik, N. and Palma-Rivas, N. (2000). Comparative Analysis of Learner Satisfaction and Learner Outcomes in Online and Face-to-Face learning Environments. Journal of Interactive Learning Research. Vol 11(1). pp $29-49$.

[17] Khan, B. H. (2005). ELearning Quick Checklist, Information Science Publishing, Idea Group Inc, Hershey PA,USA

[18] Khan, B. H. (2006). Flexible Learning in an Information Society, Information Science Publishing, Idea Group Inc,Hershey PA, USA.

[19] Khan, B. H. 2004. People, process and product continuum in e-learning: The e-learning P3 model. Educational Technology, 44(5): 33-40.

[20] Kotter, J. P. 1998. "Leading change: Why transformation efforts fail." In Harvard Business Review on Change, 1-20.Boston: Harvard Business School Press.

[21] Marshall, S. J. (2004). Leading and managing the development of e-learning environments: An issue of comfort or discomfort? In Beyond the comfort zone: Proceedings ASCILITE Perth 2004.

[22] Menchaca, M., Bischoff, M., \& Abrams, B. (2003). A Model for Systemic Change Management in Education. Paper Presented in International Conference on Education and Information Systems: Technology and Applications (EISTA $03), 26$.

[23] Nokelainen, P. (2006). An empirical assessment of pedagogical usability criteria for digital learning material

[24] Poole, M. S., \& Van de Ven, A. H. (2004). Handbook of organizational change and innovation. Oxford University Press.

[25] VanRaaij, E. M., \& Schepers, J. J. L. (2008). The acceptance and use of a virtual learning environment in China. Computers and Education 50, 838-852.

[26] Richards, L, Connolly, M., \& O'Shea, J. (2004). Managing the concept of strategic change within a higher education institution: The role of strategic and scenario planning techniques. Journal of Strategic Change, 13, pp. 345-359.

[27] Rovai, A. P., Ponton, M. K., \& Baker, J. D. (2008). Distance learning in higher education. A programmatic

[28] Russell, C, (2009) "A systemic framework for managing e-learning adoption in campus universities: individual strategies in context", Research in Learning Technology, 7 (1), 3-19.

[29] Saeedikiya, M., Mooghali, A., and Setoodeh B. 2010. Stages of the Implementation of E-Learning in Traditional Universities, Edulearn10 Proceedings, Pp. 6620-6624. 
[30] Sharpe, R., Benfield, G., and Francis, R., (2006), "Implementing a university e-learning strategy: levers for change within academic schools", Research in Learning Technology,14(2), 135-151.

[31] Sharpe, R., Benfield, G., and Francis, R., (2006), "Implementing a university e-learning strategy: levers for change within academic schools", Research in Learning Technology, 14(2), 135-151.

[32] Singh, H. (2003) Building Effective Blended Learning Programs Harvey .Issue of Educational Technology, 43, (6), 51-54.

[33] Uys, P. M. \& Tulloch, M. K. (2007). Appropriate change leadership for the introduction of flexible learning within university governance and strategic leadership frameworks: A comparative analysis of case studies in developed and developing countries. Integrating for Excellence 3rd International Conference. 27-28 June, Sheffield Hallam university.
[34] Uys, P.M. (2010). Implementing an open source learning management system: A critical analysis of change strategies. Australasian Journal of Educational Technology. 26 (7), 980-995.

[35] VanRaaij E.M. and Schepers J.J. (2008). The acceptance and use of a virtual learning environment in China. Computers \& Education,vol. 50, pp. 838-852.

[36] Ward, M., West, S., Peat, M. and Atkinson,S., "Making it Real: Project Managing Strategic e-Learning development Processes in a Large, Campus-Based University", Journal Of Distance Education, 24(1),(2010), 21-42.

[37] www.blackbaord.com, (2012) Viewed online on 23th Jan 2012.

[38] www.ju.edu.jo (2012), Viewed online on 12th Jan 2012.

[39] www.moodle.org (2012), Viewed online on 22th Jan 2012.

[40] Zwass, A. (1998). Foundations of information systems. USA: Irwin/McGraw-Hill. 496-514. 